\title{
Cinzelamento e sexualidade em Films d'amour (1968-89), de Maurice Lemaître
}

\section{Fábio Raddi Uchôa}

Pós-Doutor; Universidade Tuiuti do Paraná, Curitiba, PR, Brasil

raddiuchoa@gmail.com

\section{Resumo}

Com base no conjunto de curtas Films d'amour, realizados por Maurice Lemaître, busca-se questionar seus principais traços narrativos, tendo por foco as questões do cinzelamento e da sexualidade neles existentes. Para tanto, parte-se do debate teórico das dimensões fílmicas, extrafílmicas e líricas do cinzelamento, bem como da sexualidade no contexto da vanguarda letrista. Em um segundo momento, os filmes são abordados por uma descrição comentada, atenta às questõeschave anunciadas, bem como às contraposições letristas aos padrões hegemônicos de sexualidade próprios ao cinema clássico e ao pornô. Por fim, identifica-se a existência de uma sexualidade particular, associada ao lirismo e também às tensões entre a liberdade visual e a racionalização dos elementos sonoros/escritos. Entre os desdobramentos, quanto às teorias sobre a construção da sexualidade no cinema, defende-se que Films d'amour terá um campo conceitual propício, a partir de autores como Laura Mulvey, Mary Ann Doane e Yann Lardeau que, nos anos 70, desconfiavam do prazer visual e da sexualidade, herdeiros do naturalismo clássico e da fragmentação do pornô.

\section{Palavras-chave}

Cinema de vanguarda. Letrismo. Cinzelamento. Sexualidade. Maurice Lemaître. 


\section{Introdução}

Neste artigo, o objetivo é tratar do conjunto de cinco curtas-metragens Films d'amour (1968-89) ${ }^{1}$ de Maurice Lemaître, contextualizando-os junto ao movimento letrista, identificando alguns de seus aspectos formais e percebendo como isso colabora para uma construção particular de sexualidade. Os curtas foram realizados entre as décadas de 1960 e 80 e, posteriormente, unidos em um grupo denominado pelo artista como Films d'amour.

Ao pé da letra, o título poderia ser traduzido por "filmes de sexo", sugerindo relações com o cinema erótico em geral; por outro lado, a dupla de palavras é bastante usada para referir-se ao subgênero cinematográfico "romance", corruptela comercializada do melodrama, termo muito utilizado em videolocadoras para classificar filmes que compreendem enlaces amorosos. Tal pluralidade de sentidos tensiona-se constantemente com a sexualidade presente nas imagens - em sua grande parte, extratos de filmes com envolvimentos amorosos, por vezes explícitos. Os cinco curtas reunidos em Films d'amour são construídos a partir de fragmentos de outros filmes. Isso inclui fitas eróticas, pornôs do período silencioso e melodramas, entre outros materiais que sofrem fortes intervenções manuais, a partir de um gesto bastante consonante com as práticas letristas em geral.

Maurice Lemaître, vale lembrar, é, desde os anos 1950, uma figura fundamental para a vanguarda letrista, atuando como principal discípulo de Isidore Isou, fundador do movimento. Devido à sua fidelidade ao grupo de origem, diversas serão as consonâncias entre o tardio Films d'amour e o núcleo da cinematografia letrista realizada entre os anos 1951 e 1952. Primeiramente, trata-se de um conjunto fragmentar de imagens, construído de maneira a evidenciar os descompassos entre imagens e sons. Como em outros filmes letristas, a presença da voz over é marcante. Tais obras seriam intervenções ou performances, compreendendo imagens em movimento, projetadas em locais variados da sala, somadas à presença de atores e figurantes. Parte dessas vozes presentes nos materiais registrados, por sua vez, corresponderiam a falas planejadas para serem entoadas in loco pelos próprios artistas.

Também em sintonia com o corpus central da cinematografia letrista, Films d'amour apresenta forte contraposição ao cinema clássico e a outros cinemas, tais como o pornô -

\footnotetext{
1 Os curtas-metragens são L'Amour-système (1979), 16mm,17min; L'Amour réinvente (1979), 16mm, 15 min; Des scènes d'amour très réalistes avec force détails et gros plans (1978), Super-8, 15 min30; L'Amour, qu'est-ce? (1976-1989), 16mm, 24 min; Chantal D., Star (1968), 16mm, 26 min. Há uma outra versão para download do filme, porém reduzida, sem o filme inicial, L'Amour-système, que se encontrava disponível em janeiro de 2018.
} 
referências essas que são constantemente tensionadas, por meio da montagem fragmentar e pelas intervenções diretas sobre a película, presentes em filmes letristas. Levando em conta os jogos entre as fragmentações da matéria fílmica e da narrativa, denominadas pelos letristas de cinzelamentos, e o tratamento da sexualidade, pode-se pensar em operações de contravenção ante uma cultura patriarcal hegemônica, típica de extratos do cinema clássico e do pornô. Nesse sentido, há uma operação transgressora, que se apropria de extratos audiovisuais associados a uma cultura do olhar masculino e que toma o corpo feminino como objeto, atacando-os e levando-os a uma explosão. Entre os resultados, há uma reordenação em torno de um lirismo dos próprios estímulos visuais e sonoros transformados em matéria com conotação sexual.

Quanto à definição da transgressão letrista, pode-se pensá-la em contraposição ao clássico, em um contexto de consolidação de vertentes modernas europeias e de recolocação de anseios de vanguardas anteriores. Entre as teorias que retomam tais anseios, vinculandonos ao debate da sexualidade no contexto dos anos 1970, há possíveis contatos com as ideias de Laura Mulvey (1983) e Mary Ann Doane (1983), especialmente com suas propostas de questionar a imagem da mulher e, associado a isso, o prazer visual e sonoro como construções sociais associadas a uma cultura patriarcal do cinema clássico.

Nesse sentido, retoma-se de Mulvey, a ideia de um cinema dominante, "[...] que codificou o erótico dentro da linguagem da ordem patriarcal dominante [...]" (1983, p. 440), apresentando processos de voyeurismo e identificação, que têm por centro o olhar e o prazer masculinos. De Doane (1983), a noção de um prazer sonoro associado às elaborações sincrônicas próprias ao mesmo cinema mainstream e que seria contraposto a partir de assincronias; para a mesma autora, há casos do cinema moderno que chamam atenção por certos usos da voz over, especialmente quando multiplicada, como no caso letrista, atentando às vozes em suas plasticidades, dispersões, fragmentações e perdas de unidade em relação aos corpos (DOANE, 1983, p. 472-73).

Faz parte das indagações, portanto, averiguar as tensões da cinematografia letrista erótica ante às formas de ver hegemônicas, contestadas por Mulvey (1983) e Doane (1983). 0 atrito letrista, vale lembrar, será também contra o pornô, especialmente em sua vertente que reafirma uma cultura voltada ao prazer masculino, tendo entre seus traços: a hiperfocalização do sexo, a aproximação microscópica e a divisão sistemática do espaço, desdobrando-se em um tipo de prazer milimetricamente programado (LARDEAU, 1978). Em oposição a tal pornô, os filmes de Lemaître tendem a explodir e reordenar os fragmentos, 
unindo-os a partir de uma nova lógica, predominantemente lírica. Ou seja, uma ordenação na qual os diferentes movimentos, estímulos e asperezas audiovisuais parecem dizer respeito à própria experiência de mundo dos letristas, em seu ataque à arte acadêmica e ao cinema como janela para o mundo.

Partindo de tais indagações, seguiremos um trajeto particular pelo cinema letrista e pela obra de Maurice Lemaître, abarcando definições teóricas, influências líricas e narrativas do cinzelamento, bem como uma descrição comentada dos filmes. Isso, para posteriormente retomar as particularidades de Films d'amour em suas contravenções a um prazer erótico, fundado no olhar masculino e na identificação naturalista dos corpos em suas performances. Em Films d'amour, de modo particular, há uma sexualidade associada a experiências líricas, especialmente atentas aos ritmos e asperezas audiovisuais, bem como a um jogo de ambivalências entre a liberdade e a racionalização, já presentes em parte da literatura erótica letrista e com influências sobre os filmes Lemaître.

\section{0 letrismo e Maurice Lemaître}

O letrismo é uma vanguarda do pós-guerra, herdeira do dadaísmo, do futurismo e do surrealismo. Inicia-se na segunda parte da década de 1940, com a viagem do romeno Isidore Isou a Paris, cidade na qual publicaria Introduction à une nouvelle poésie et à une nouvelle musique (ISOU, 1947). 0 grupo inicial se organizaria em torno da poesia fonética, proposta por Isou como uma união entre música e poesia. Entre as principais propostas letristas, encontram-se: (1) a ação da vanguarda enquanto atividade de dissolução de campos da arte e do conhecimento; (2) a retomada da poesia fonética, anteriormente presente entre os futuristas e dadaístas, por eles considerada como um novo tipo de poesia; (3) a criação de novos intervalos, atividade que seria aplicada às diferentes frentes artísticas, incluindo poesia, literatura, artes plásticas, teatro e cinema.

As poesias, mescladas ao universo da música, seriam denominadas de lettries, tomando-se as sonoridades vocais e percussivas do corpo como base para uma outra linguagem, redigida a partir da invenção de novas formas de grafia. Nas artes plásticas, por sua vez, as práticas envolveriam o uso da tela como espaço de interação entre diferentes artes - em particular a fotografia, a escrita e a pintura -, culminando em colagens desses diferentes tipos de registro (denominados hipergrafias). Já na literatura, haveria uma mescla entre escrita e pintura, com a realização daquilo que ficou conhecido como "romance 
hipergráfico" (SABATIER, 2000, p. 27, tradução nossa) , unindo pesquisas pictóricas e escritas, a partir da coexistência dessas duas formas de notação. Quanto à sétima arte, por fim, seria tomada como uma mistura entre cinema e teatro, envolvendo a presença de performances durante as projeções, o que seria por eles denominado "cinema discrepante" (LEMAÎTRE, 1954, p. 102, tradução nossa).

Entre as diferentes vertentes artísticas visitadas, parece haver um gesto artístico compartilhado cujas particularidades são, em parte, sugeridas por alguns dos pesquisadores do letrismo. Assim, para François Albera (2009), haveria um negativismo criador em tal gesto, em parte inspirado no Dadaísmo. Se o Dadá promovia uma dissolução da arte a partir do ready-made, das performances provocadoras e de uma poesia que já dissolvia as palavras, tal gesto ganha continuidade no caso letrista, tendo por trás algum intuito de construção. Assim, em seu Manifeste de la poésie lettriste, de 1947, Isidore Isou indica que, sob as lettries, haveria uma nova arquitetura de ritmos ou de significados flutuantes, presentes nas recorrências rítmicas e sonoras inventadas. (ISOU, 1947, p. 16-18).

Para o caso do cinema, Aumont e Marie (2003) sugerem que os letristas realizariam uma síntese e radicalização de estéticas anteriores, transpondo-as ao cinema, tendo como principais traços a ruptura do sincronismo entre imagens e sons somada à intervenção sobre velhas películas, raspando-as. No cinema, portanto, nega-se a clássica continuidade imagem-som, não sem a proposta intuitiva de novos padrões, especialmente fundados na assincronia. Em alguns casos, atentando para as discrepâncias entre imagens, sons e ações, haverá a definição do cinema letrista pela relevância daquilo que está fora da tela. Para Kaira Cabañas (2014), o cinema letrista seria um off-screen cinema, marcado por um duplo desvio: a negação da primazia da imagem somada à contraposição das possíveis dominações exercidas pelo espaço da sala.

O primeiro grupo letrista será constituído entre 1946 e 1951, em torno de Isidore Isou, envolvendo alguns de seus discípulos, como Gil Wolman, Maurice Lemaître, Gabriel Pomerand, François Dufrêne e Guy Debord. 0 ano de 1952, por sua vez, marcará a primeira cisão interna do grupo, com o início de uma segunda fase. A partir de então, Debord e Wolman se autodesignarão como uma vertente de esquerda reunida em torno da Internacional Letrista, ${ }^{2}$ enquanto outros letristas continuarão às voltas de Isou e Lemaître. 0

\footnotetext{
2 A ruptura promovida pela Internacional Letrista será declarada a partir de outubro de 1952, contexto no qual a presença de Chaplin em Paris, associada à divulgação de Limelight, 1952, seria fortemente contestada por membros da esquerda do grupo, incluindo entre eles G. Wolman, G. Debord, Sege Berna e Jean-Louis Brau. Entre 22 de junho de 1954 e 5 de novembro de 1957, a Internacional Letrista se constituirá como boletim de divulgação das ideias do grupo, com um total de 27 volumes publicados (DEBORD, 1996, p. 7).
} 
cinema letrista seria inaugurado um ano antes de tal cisão, em 1951, tendo entre suas principais obras: Traité de bave et d'éternité (1951), de Isidore Isou; Le film est déjà commencé? (1951) de Maurice Lemaître; L'anticoncept (1952) de Gil Wolman; Hurlements en faveur de Sade (1952) de Guy Debord. Sobre as principais caraterísticas de tais obras, podemos destacar certa autonomia entre imagens e sons, enfatizando-se o som como polo gerenciador; outro dos traços será o ataque à tela como local de projeção, sendo por vezes abolida e permitindo outros usos da antiga sala escura, tais como a performance e a declamação de poesias.

A obra de Lemaître terá grande coerência com o grupo inicial. Integrando-se ao movimento em 1950, após ter escrito para os jornais Libertaire e Combat, o artista produzirá frenética e constantemente durante mais de 50 anos. Seu trabalho abrangerá diferentes frentes, tais como a edição de revistas, o cinema, a pintura, a literatura e a poesia. Será um discípulo exemplar de Isou, colaborando para a edição e divulgação de sua obra, atuando na organização de exposições do grupo, bem como cooptando colaboradores em períodos de crise.

No caso particular do cinema, além de compartilhar os descompassos imagem-som e o ataque à tela enquanto único local de experiência, em sintonia com o cinema letrista dos anos 1950, a obra de Lemaître se destacará pelas performances na sala de projeção. Seu primeiro longa, Le film est déjà commencé?, foi concebido como um cinema-teatro, com um roteiro que incluía as ações dos atores. 0 livro homônimo, de publicação contemporânea às projeções de Le film est déjà commencé?, resume os principais direcionamentos do cinema de Lemaître. Isso inclui a plateia como local de experiências cotidianas a serem somadas ao espetáculo geral, bem como as diretrizes para os atores, que fariam intervenções planejadas (LEMAÎTRE, 1999). De fato, as propostas de Lemaître pressupunham a contratação de um conjunto de atores profissionais, treinados espacialmente para romper com as possibilidades de fruição e identificação por parte dos espectadores. Visando às ações extratela, algumas das obras de Lemaître seriam acompanhadas por roteiros, falas complementares à projeção ou mesmo cartelas projetadas antes do filme; haveria também folhetos distribuídos entre os presentes, com indicações sobre as condições ideais de projeção.

Films d'amour (1968-89) aproxima-se de tal matriz do letrismo, incluindo coerências com a obra cinematográfica de Lemaître em geral. Apesar da abrangência temporal, neles intriga a grande continuidade quanto aos principais traços de composição. Trata-se de um 
conjunto de curtas construídos a partir de imagens que sofrem fortes intervenções manuais. Suas bandas sonoras, compostas majoritariamente por discursos, diálogos ou poesias, relacionam-se com as imagens através de diferentes assincronias. Parte dos folhetos e informações que acompanhavam suas seções, por sua vez, sugere a permanência das encenações e provocações in loco. Tais aspectos narrativos, contrários ao cinema clássico, são articulados para a construção de obras, sob as quais a sexualidade está implícita enquanto referência sonora ou visual.

Com o objetivo de preparar o campo para o debate de Films d'amour, mapearemos, nos próximos tópicos, duas questões de importância para os letristas: (1) a noção de cinzelamento, abrangendo as intervenções sobre a película e as cisões imagem-som; (2) o tratamento da sexualidade no letrismo, tomada como um ramo técnico do conhecimento, presente especialmente nas propostas de Isidore Isou e Maurice Lemaître.

\section{0 cinzelamento e suas potencialidades líricas}

No âmbito do letrismo, o cinzelamento pode ser pensado como um trajeto teleológico em um mundo marcado por dois momentos sucessivos. Por um lado, o momento denominado amplique, no qual as técnicas são utilizadas em harmonia; por outro, haveria um momento ciselant, de saturação, com maior presença do fragmento e da dissolução das frentes artísticas. 0 cinzelamento, nesse caso, seria um movimento inerente à ação e à construção do conhecimento, que pressupõe a necessária passagem do amplique ao ciselant. No caso do cinema, os artistas letristas consideram que estariam realizando a transição do cinema amplique para uma nova existência ciselant.

Em uma possível teoria letrista do cinema, o cinzelamento associa-se à defesa de um “cinema discrepante" (LEMAÎTRE, 1954, p. 103-108, tradução nossa), também chamado de syncinema. No manifesto em defesa de tal cinema3 ${ }^{3}$, originalmente publicado em 1952, Lemaître destaca, entre os principais preceitos: o ataque ao cinema como arte de técnicas usadas em harmonia; a montagem discrepante, com a autonomia entre sons e imagens, estimulando um desenvolvimento narrativo independente; os sons gravados antes das imagens, libertando-se da tirania da visão; a destruição do roteiro em sua forma clássica; o questionamento dos usos da tela, em alguns casos, ambicionando-se atravessá-la, destruí-la; bem como a mescla entre cinema e teatro, a partir da inclusão da sala enquanto parte do

3 “Notes pour un syncinema." (LEMAÎTRE, 1999, p. 56-83). 
espetáculo cinematográfico. Tais reivindicações teriam influências diretas sobre a imagem, o som e a sala de projeção.

0 cinzelamento, em uma acepção mais restrita, diz respeito à ação sobre a película. Alguns roteiros sugerirão uma espécie de dicionário para a construção do cinzelamento. Nessa frente particular, percebe-se algo muito próprio ao letrismo: a criação de uma forte sistematização teórica, que busca explicar uma estética/prática cuja aparência final é extremamente anárquica. Teorizavam-se tais sistematizações em roteiros, tais como aquele de Le film est déjà commencé?; nele, apesar do efeito visual anárquico, Lemaître racionaliza modos de intervenção para a contraposição da continuidade clássica: exposição visual da banda sonora da película; alternâncias planejadas entre sequências completamente negras ou brancas; mescla violenta em termos de imagens, envolvendo extratos de filmes de gênero; tachismos obtidos pela ação com aerógrafo sobre o negativo; alternância de tingimentos; inserção de subtítulos; desenquadramentos; submissão das películas a banhos de ácido, seguidos de intervenções com escovas; bem como a superposição de três ou quatro películas, de modo a obter magmas de imagens (LEMAÎTRE, 1999, p. 99-173). 0 cinzelamento é, nesse caso, uma gama de intervenções de modo a abalar a continuidade e a transparência clássicas, que são complementadas, em alguns casos, pelas intervenções teatrais dos atores e figurantes, de modo a desviar a atenção.

Um terceiro sentido para o cinzelamento, por fim, desdobra-se da já referida oposição à continuidade clássica, a partir da cisão entre sons e imagens. Apesar dos escritos de Lemaître referirem-se simplesmente à primazia do som sobre as imagens, há uma enorme gama de descompassos, que podem ser pensados a partir da assincronia audiovisual. Diversas são as formas: da emissão sonora sobre fundo negro (caso de The song of Rio Jim, 1978), ao recitar de poesias fonéticas sobre experiências visuais (caso de $O$ amor reinventado, 1979). Ocorrerá também em experiências nas quais há uma emissão sonora central, rodeada por imagens que lhe parecem ser alheias ${ }^{4}$ e suas variações, para construções nas quais sons e imagens colocam-se como cadeias de estímulos paralelos, contendo convergências e conflitos pontuais. Em todos esses casos, a sincronia clássica é corrompida, incluindo desdobramentos sobre a construção dos corpos: no primeiro, trata-se de corpos imaginados, mentalmente projetados sobre a tela negra; nos demais casos,

\footnotetext{
${ }^{4}$ Caso de assincronia explorado por Michel Chion (1993), associado aos noticiários televisivos, nos quais nota-se uma emissão sonora rodeada por imagens que lhes são alheias. A figura pode ser aproximada de casos de filmes de Marguerite Duras e da cinematografia letrista.
} 
possíveis variações de corpos desmaterializados, cujos fragmentos em assincronia tornamse manchas de superfície, com pouca ou nenhuma densidade diegética.

O cinzelamento pode assumir, assim, diversas acepções, aproximando-se de: (1) uma forma de construção do conhecimento, ou período na evolução das artes, com a sucessão do amplique pelo ciselant; (2) uma contraposição à continuidade clássica, incluindo a ação gráfica sobre a película e as provocações à plateia; ou ainda, c) uma forma de construção assincrônica entre imagens e sons.

Em termos estéticos, as variadas intervenções sobre o celuloide propiciam um achatamento da perspectiva, além de novas lógicas de leitura, envolvendo pulsações, cintilações e asperezas, que permitem aproximações ante ao assim denominado cinema lírico. Consolidado, de modo mais enfático, entre as experiências cinematográficas de Stan Brakhage e as definições de Adam Sitney (2002), trata-se de um tipo de cinema no qual o realizador, atrás da câmera, seria o principal protagonista. A tela, repleta de movimentos incluindo aqueles decorrentes da edição -, reverberaria a experiência e o olhar de tal diretor ante ao mundo, afirmando um tipo de imagem cujo achatamento e uso expressivo das cores se contraporiam às construções da decupagem clássica (SITNEY, 2002). Tal cinema associase também a um olhar interno, livre das leis clássicas da perspectiva. Promove uma percepção aberta às possibilidades do onírico e às figuras abstratas daquele que esfrega as pálpebras com os olhos fechados. Somam-se a tais experiências: as diferentes velocidades, exposições e filtros, além das ações de raspar ou criar rastros de tinta sobre a película. (BRAKHAGE, 1983) ${ }^{5}$.

Com suas devidas particularidades, os cinzelamentos em alguns dos filmes letristas, especialmente aqueles de Isidore Isou e de Maurice Lemaître, podem ser pensados em suas dimensões líricas. As intervenções sobre celuloide, ou envolvendo o extratela, resultam em um tipo de percepção alternativo que, diferente do lirismo cinematográfico de Brakhage, abrange uma experiência coletiva sobre o mundo. Se existe uma percepção interna, ela explicita, a todo momento, um desejo coletivo de ruptura voltado à narrativa clássica, à película, ao cinema e também às disciplinas do campo artístico e das humanidades. No caso particular de Films d'amour, há passagens nas quais a ação de ruptura se soma às dimensões sexuais das imagens e sons, trazendo uma percepção lírica da sexualidade, pautada pelos

\footnotetext{
5 Em Off Screen Cinema Cabañas sugere contatos efetivos, via correspondência, existentes entre Stan Bakhage e dois dos principais cineastas letristas, Isidore Isou e Maurice Lemaître. Em seus diálogos, haveria trocas de informações sobre a circulação de filmes letristas nos EUA dos anos 1960, mas também o reconhecimento, por parte de Brakhage, da importância de Traité de bave et d'éternité, de Isou, como inspiração direta para o desenvolvimento de sua poética cinematográfica pessoal (CABAÑAS, 2014, p. 135-139).
} 
ritmos, pulsações e asperezas. 0 som, por vezes, assume-se como mais uma das matérias e texturas em jogo na construção de emaranhados de estímulos. Em suas dimensões líricas, constrói-se uma sexualidade antinaturalista, oposta a um prazer restrito à dimensão visual, das formas, faces, corpos ou presenças visíveis dos seres humanos no mundo.

\section{A questão da sexualidade no letrismo}

A sexualidade apresenta-se em diversas das realizações letristas. Na literatura, ela será debatida por Isidore Isou em sua erotologia - uma frente técnica de estudo da sexualidade, fundada pela união da psicologia, da sociologia, da matemática e dos estudos do erotismo. A proposta estará presente em diversos escritos, partindo de Isou ou la mécanique des femmes (ISOU, 1949), e ganhando densidade especialmente em Je vous apprendrai l'amour suivi de Traité d'érotologie mathématique et infinitésimale (ISOU, 1959).

0 primeiro desses livros levará Isou a ser condenado a oito meses de prisão e à queima dos livros pela justiça francesa, pena da qual seria anistiado em 1953. Assim como em outros contextos da prática artística letrista, Isou ou la mécanique... inclui em sua concepção a coexistência de duas tendências aparentemente opostas: por um lado, a experiência anárquica, nesse caso presente na potência instintiva da aproximação sexual; por outro lado, a sistematização teórica, com a concepção do mundo a partir de equações e leis matemáticas.

No segundo desses livros, Je vous apprendrai l'amour..., destaca-se a liberdade de escrita, presente na desenvoltura e na não-censura ao tratar de temas e detalhes eróticos, que convive com a forte sistematização de regras para os envolvimentos amorosos, em particular para o ato de sedução. Em sua primeira parte, trata-se de um diário íntimo, escrito em primeira pessoa, narrando as experiências de um galanteador de mulheres. Como questão de fundo, a aplicação de um manual da sedução que, se não é infalível, ao menos possui rendimentos precisos (ISOU, 1959). Já na segunda parte do livro, propõe-se uma teoria com pretensões científicas, tendo por objeto um mapeamento das posições e situações sexuais. Trata-se de unir estudos, em particular, sobre a sexualidade e a matemática. Intui-se um sistema de equações matemáticas que seria composto pelas diferentes formas de aproximação sexual. Os próprios letristas farão referência a tal teoria, a partir de sua abrangência e pretensiosismo. Para o artista Roland Sabatier, trata-se de uma visão coerente e rigorosa dos domínios do amor. Na ação humana, sua síntese estaria 
relacionada a um movimento evolutivo e orgânico, fundado "no setor da aquisição sensual, contendo dados biológicos, psicológicos, econômicos e culturais, definidos como uma mecânica herdada da paixão." (SABATIER, [20--]).

\section{Cinzelamento e sexualidade no cinema: films d'amour}

Para o debate do cinzelamento e da sexualidade no cinema de Lemaître, o foco será conjunto Films d'amour, com cinco curtas-metragens: L'amour-système (1979), L'amour réinventé (1979), Des scènes d'amour très réalistes avec force détails et gros plans (1978), L'amour, qu'est-ce? (1976-1989) e Chantal D. Star (1968), que guardam grande relação entre si. Foram realizados em 16mm e super-8, com posterior reedição em VHS nos volumes 03, 07 e 10 das obras completas de Lemaître (Oeuvres de Cinema - Avantgarde Video/Centre de Creativité) ao longo dos anos 2000. Também apresentam continuidades em torno da temática da sexualidade: incluem diversos extratos de filmes pornôs silenciosos, melodramas ou mesmo home movies, nos quais existem envolvimentos amorosos ou apenas a referência ao ato sexual.

Em tais filmes, a sexualidade será tomada como releitura explosiva do cinema pornô ou então enquanto ironia a um suposto amor melodramático do cinema clássico. Como na cinematografia de Lemaître em geral, notamos a reincidência da tensão "experiência anárquica versus teorização", especialmente entre o lirismo das configurações visuais e, por outro lado, a racionalização presente nas anotações de projeção ou em parte dos comentários sonoros. Além do tensionar dessas duas tendências, há também um jogo voraz com as sexualidades presentes nos materiais de origem, com a construção de uma nova sensualidade, atenta aos fluxos e asperezas visuais e sonoras. Films d'amour é um conjunto particular de curtas que, dentro da obra de Lemaître, incorpora as questões do cinzelamento, da sexualidade e das tensões entre liberdade e racionalização. Eles serão aqui abordados a partir de uma descrição comentada6 ${ }^{6}$, levando em conta suas particularidades temático-narrativas, especialmente voltadas às interfaces entre cinzelamento, sexualidade e tendências líricas.

\footnotetext{
${ }^{6}$ Serão aqui articuladas operações denominadas por Aumont e Marie (2002), em L'analyse du film, como "instrumentos descritivos" e "instrumentos documentais" (AUMONT; MARIE, 2002). A descrição abrangerá um nível bastante amplo, identificando os dispositivos gerais, bem como as recorrências narrativas, relativas às construções visuais e sonoras; elementos esses que serão complementados com documentos sobre os filmes, incluindo anotações de Lemaître e indicações de projeção.
} 
L'amour-système abre a sequência de curtas-metragens. Pelo título, poderia passar-se por um filme pornô ou um documentário sobre as relações amorosas entre seres humanos. 0 jogo de expectativas em torno de uma performance amorosa, cujas palavras remetem à liberdade e à ordenação, revela-se como ironia desde os primeiros momentos do filme. A versão aqui debatida ${ }^{7}$ possui três minutos de duração, e seu dispositivo é basicamente uma tela de fundo negro, sobre a qual escutamos declamações letristas. Um breve prólogo indica as frases de abertura, que seriam ditas pelo narrador da sessão. Entre as principais ideias, há a autodenominação como um filme de vanguarda e o menosprezo pelo cinema de grande público. 0 principal tema de interesse seria o filme com imagem totalmente negra, já tratado por Lemaître em outras obras, como The song of Rio Jim, de 1978, Nada ou le dernier film, de 1978. Posteriormente, passa-se à voz de Maurice Lemaître, registrada sobre tela negra, recitando uma poesia cujo lema é "Grito inimaginável e inaudível”, que ocupará a quase totalidade da duração da fita.

Figura 1 - Frames de L'amour-système (1979)
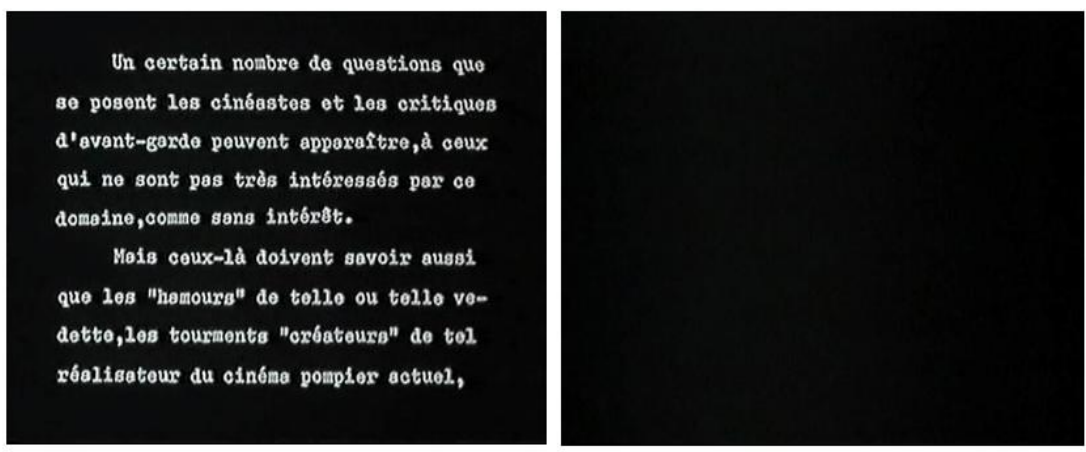

Fonte: Fotogramas captados pelo autor, adaptados do filme L'amour-système (1979).

L'amour-système parte, portanto, de uma negação dupla. 0 descompasso entre obra e título rompe com a expectativa de uma performance erótica-amorosa que, por sua reincidência no imaginário ocidental, poderia ser aquela guiada pela exposição do corpo feminino a partir de um olhar masculino. A segunda negação diz respeito à forma: ao invés de uma recepção passiva de imagens, a ação exigida do espectador envolve uma projeção imaginária. Trata-se de uma atividade transformadora, que inclui a presença de um atorapresentador cuja voz se torna a principal linha de criação de sentidos, em diálogo com o fundo negro.

\footnotetext{
7 Verão utiliza da de <https://www.artcitytv.com/>. Há uma outra versão, em VHS, incluída em Oeuvres de cinema.
} 
Já o grito, tematizado pela trilha sonora de L'amour-système, retomando a potência do cinzelamento letrista, trabalha com a ruptura do silêncio pela voz das minorias excluídas. Tais minorias seriam raciais, políticas, de classe e de gênero. Entre elas, estão incluídos os algerianos, os jovens poetas comunistas, os refugiados da guerra civil espanhola, assim como as mulheres - as operárias de usinas, as mulheres da Libéria ou aquelas que são massacradas pela ordem oficial do sexo. Em síntese, trata-se da proposta de um grito inaudível daqueles que não têm voz, a partir de um filme sem imagens, mas cujo fundo negro é local de transformação. A expectativa por um filme de gênero erótico, anunciada pelo título, é substituída por um filme-manifesto, cuja política é contrapor-se a uma suposta ordem oficial do sexo, a partir de uma forma que coloca em xeque o prazer visual e a sincronia naturalista do cinema clássico.

Alguns dos filmes letristas podem possuir versões modificadas ao longo das experiências de projeção (LEMAÎTRE, 2003). Nas anotações de projeção da versão inicial de L'amour-système, o acompanhamento vocal era outro. 0 ator recitaria trechos do livro homônimo Le journal d'un dragueur ou L'amour-système, obra literária escrita por Lemaître (1960) e bastante próxima à erotologia de Isidore Isou. Trata-se, basicamente, do diário de um galanteador, que incorpora a liberdade da escrita e, por outro lado, a teorização das aproximações sexuais por meio de experimentos e tipologias. Nesse caso, em sua proposta inicial, a expectativa erótica do título de L'amour-système seria reafirmada pelo conteúdo erotológico do conto verbalmente narrado. A tela negra corresponderia, assim, ao local de projeção de uma imaginação literária, com a reafirmação da dualidade liberdade versus teorização, presente no conteúdo narrado, mas também na própria forma da obra, cujo cinzelamento opõe a fluidez verbal da trilha sonora e o retesamento conceitual do fundo negro.

O segundo curta-metragem da série, L'amour réinventé, por sua vez, aproxima-se de uma sinfonia. Possui alguns padrões audiovisuais que se sucedem, com variações, aumentos e diminuições de intensidade. Tais tensões aproximam-se de algo animal ou orgânico, com a sugestão de um lirismo não distante de filmes de Stan Brakhage - caso de Window, water, baby, moving, de 1959, cuja montagem poderia aproximar-se das contrações de um parto humano, ou de Mothlight, de 1963, que articula um suceder de composições visuais. A estrutura geral de L'amour réinventé divide-se em três movimentos ${ }^{8}$. Ou seja, uma sequência de imagens iniciais é repetida com variações em termos de cinzelamentos, extratos sonoros

\footnotetext{
${ }^{8}$ Em termos gráficos, isso poderia ser disposto da seguinte forma: ( A' | A" | A"' ), sendo A uma sequência-matriz repetida em três variações.
} 
e a inserção de novos planos. Trata-se de uma colagem de sequências provenientes de diversas origens, contendo um conjunto básico que é repetido, junto com um aumento progressivo de tensão.

Entre os materiais reprocessados em L'amour réinventé, predominam imagens que, originalmente, confirmam o protagonismo do olhar masculino em uma ação voyeurística que toma o corpo feminino como objeto de prazer. São extratos de filmes pornôs: os planos de detalhe dos seios de uma mulher, planos de detalhe de uma moça com as pernas abertas (aparentemente após um ato sexual), um movimento de câmera percorrendo um busto feminino nu, entre outras imagens que são montadas sob uma plasticidade que as aproxima do êxtase.

Em termos de cinzelamento visual, há quatro formas de ação sobre a película que interagem entre si, com uma negação cada vez maior das imagens de origem: (1) primeiramente, o terço inferior de cada frame ocupado por uma tarja negra, pela qual dispõem-se informações gráficas; (2) uma série de frases percorre o espaço geral da tela, incluindo homenagens a Sade, Stroheim, Lênin, Méliès, Jean Vigo, Eisenstein e Chaplin; (3) há ainda uma série de desenhos coloridos, pincelados ou talhados sobre a emulsão, que desfilam em flashes aleatórios - uma bailarina, cruzes, borboletas, figuras circulares, números e palavras dispersas; (4) além das granulações propiciadas por banhos em ácidos.

A interação entre tais ações sugere um novo olhar sob um erotismo que não está na imagem verossímil, mas sim nos ritmos e plasticidades. Tudo se passa como em um grande devaneio erótico, para o qual também colaboram os paralelismos som-imagem. 0 extrato inicial do filme, por exemplo, remete-nos a uma sensualidade orgânica: os movimentos sensuais, de uma mão apalpando um peito feminino, são ritmicamente acompanhados pela poesia "Nikazizu (balade)" datada de 1963, de Lemaître, cujos coros vocais reproduzem movimentos que poderiam ser de um grupo de Vikings remando em alto mar. Posteriormente, o mesmo apalpar será ritmicamente acompanhado por "Hymne a Xochipilli", de 1961, cujas repetições da palavra inventada "Xochipilli" remetem a algo ao mesmo tempo militar e sexual. Em outros momentos, porém, os extratos sonoros incluirão murmúrios jubilosos, que reafirmam o êxtase das imagens.

Assim, tomando-se L'amour réinventé como um grande devaneio erótico, identifica-se um anárquico balé de cinzelamentos, com um lirismo atento aos ritmos e plasticidades, para o qual colabora a própria composição sonora. Em algumas passagens, as construções 
sonoras atuarão de modo inverso, pela afirmação de ambivalências, especialmente entre o êxtase visual e o a racionalidade rítmica de algumas das poesias.

Figura 2 - Frames de L'amour réinventé (1979)
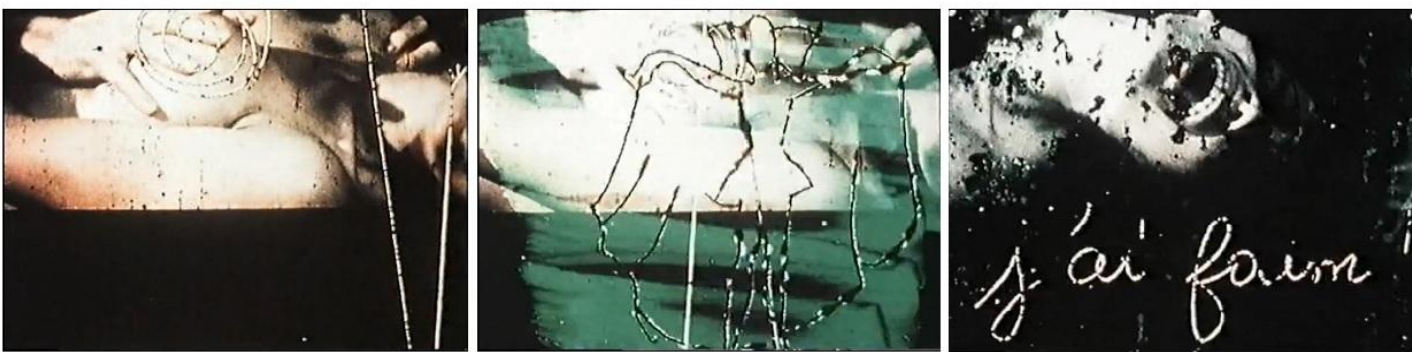

Fonte: Fotogramas captados pelo autor, adaptados do filme L'amour réinventé (1979).

Em Des scènes d'amour très réalistes avec force détails et gros plans (1978), um conjunto de sequências pornôs é repetido sob diversas formas de fragmentação e intervenção. Ao contrário de L'amour réinventé, os materiais de origem parecem fazer parte de uma história propriamente dita, com o esboço de algumas ações, que são atacadas. Um homem acorda ao lado de uma mulher e propõe a ela uma rápida cópula. Depois disso, os dois são vistos em nova atuação sexual, envolvendo-se com um grupo de outras mulheres, ou então um amor apenas entre as mulheres. Os fragmentos de imagens desse pornô são embaralhados e repetidos, acompanhados por comentários em uma língua irreconhecível. Tais conversas assemelham-se a uma aula universitária, em tom monótono, sugerindo um retesamento que contrasta com a liberdade de movimentos e cores azuladas presentes nas imagens. A montagem, por sua vez, joga com um embaralhar cada vez mais intenso das ações. Em um dos ápices, as imagens transformam-se em um jogo de borrões, seguidos pela repetição e paralização de gestos. No final, a negação das imagens volta-se para o próprio filme, tratado enquanto matéria visual projetada. A palavra "fim" será apagada pela ação de um pincel, que vemos, pincelada a pincelada, cobrindo a tela com tinta negra.

Em Des scènes d'amour..., joga-se com o olhar pornô do material de origem e sua negação, atingida pela fragmentação dos planos e do campo visível. Quanto aos cinzelamentos, novamente há uma experiência visual extremamente livre, construída a partir de padrões de intervenções bastante premeditadas. Entre as formas de intervenção, nota-se cinco linhas principais de criação de sentido: (1) a viragem azul, por vezes com borrões de outras cores; (2) banhos de ácido, sugerindo texturas; (3) rabiscos diretos sobre a película, aleatórios ou geométricos, impedindo a visualização dos personagens e seus 
corpos; (4) figuras disformes de tinta, dispostas também de modo a impedir a visão dos corpos; (5) a exposição da emulsão em sua materialidade cindida ou deformada.

O jogo culmina com a saturação e a atenção à superfície; em suas anotações, Lemaître (2007) sugere que tal saturação foi pensada como modo romper com estereótipos. Trata-se de explicitar a própria cegueira de espectadores acostumados aos padrões socialmente instituídos da sexualidade e, em particular, do pornô. Com o objetivo de deformação, previa-se exibir o filme em um projetor empoeirado, que traria às imagens uma "forma não retangular”, “[...] por causa do acúmulo de elementos, imprevistos ou inseridos voluntariamente em todas as partes do projetor, susceptíveis de trazer uma deformação à imagem (janela, lente, etc.)." (LEMAÎTRE, 2007, p. 93).

0 ataque seria reforçado, na sala, pela desorientação sonora, com presença de uma torre de rádio, que difundiria um programa local. Em Des scènes d'amour..., portanto, o cinzelamento dá-se primordialmente sobre a película, a partir de cinco tipos de intervenção principais, sob um projeto geral de negação das imagens e dos estereótipos do pornô. Tal ação é complementada pelo uso do espaço da sala e também pelas tensões entre a liberdade visual e o retesar sonoro. 0 lirismo predominante é aquele de um olhar pornô negado, substituído pela atração às massas e balés, que tomam a superfície da tela.

Figura 3 - Frames de Des scènes d'amour... (1978)
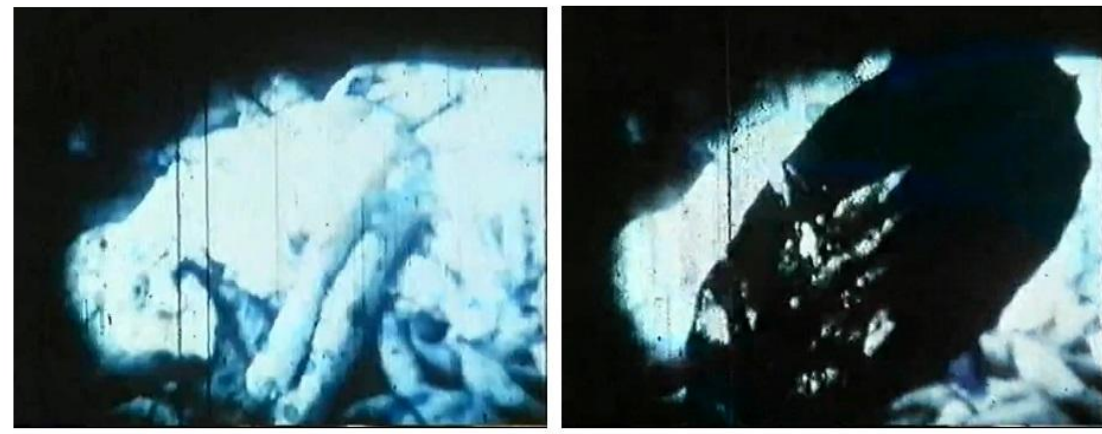

Fonte: Fotogramas captados pelo autor, adaptados do filme Des scènes d'amour... (1978).

L'Amour, qu'est-ce? (1976-89), outro dos filmes organizados em Films d'amour, retoma a construção da sexualidade entre a liberdade e a teorização, divididas aqui entre a instintividade sexual cotidiana e as formulações acadêmicas sobre o amor. 0 filme é composto, basicamente, pela repetição de duas sequências. Na primeira, possivelmente extraída de um pornô, o encontro de um senhor com uma prostituta nos momentos que precedem o ato sexual. Entre as principais ações identificáveis, percebe-se a moça despindo- 
se e jogando as vestimentas sobre as mãos do freguês, que as cheira em um gesto de êxtase. Já a segunda das sequências, extraída de um melodrama, explicita uma relação burguesa de domínio de um homem sobre sua mulher. Repetindo a tendência de Des scènes d'amour..., as duas sequências são repetidas, com variações quanto à fragmentação da montagem e às intervenções sobre a película. A instintividade sexual do homem que cheira a roupa da prostituta, assim, soma-se à sensualidade dos fluxos, formas e cores cintilantes, resumindo aqui a tendência anárquica de L'amour, qu'est-ce? (1976-89). Já na sequência melodramática, na qual o homem considera a mulher como uma propriedade privada, as ações sugeridas pelo diálogo legendado são agredidas por meio das intervenções com rabiscos ou borrões em cores. Há quatro padrões principais identificáveis entre as intervenções: (1) texturas conseguidas pelo banho das películas em ácido; (2) viragem azul, com algumas sobreposições em vermelho; (3) flechas, cruzes, desenhos e nomes, rabiscados diretamente sobre a emulsão; (4) intervenções mais drásticas, explicitando a emulsão em suas deformidades.

Figura 4 - Frames de L'amour, qu'est-ce? (1976-89)
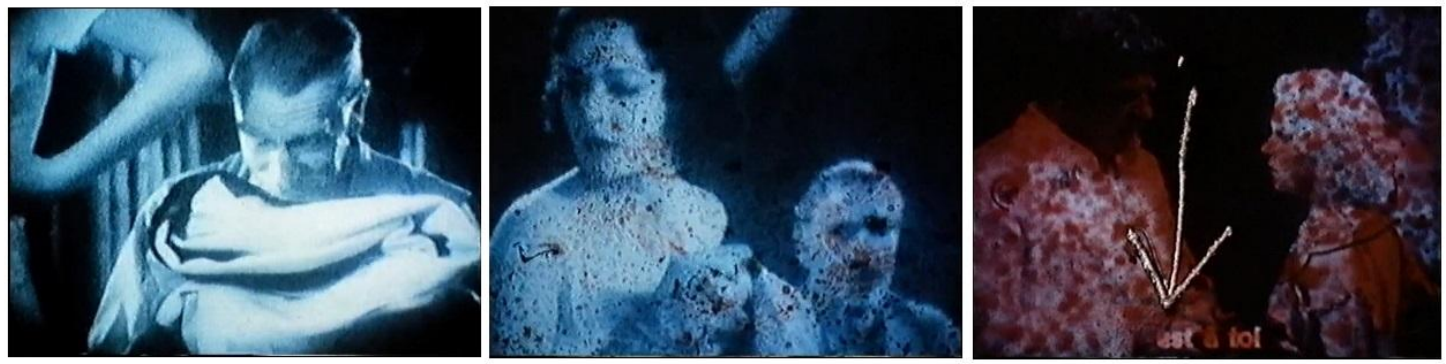

Fonte: Fotogramas captados pelo autor, adaptados do filme L'amour, qu'est-ce? (1976-89).

Paralelamente a tais imagens, na banda sonora, corre um monólogo de Lemaître em tonalidade acadêmica. 0 registro é a leitura do projeto não realizado de L'amour, qu'est-ce?, que seria uma coleta de depoimentos sobre o amor, com artistas, cineastas e políticos ilustres. Em um passo a passo ordenado, tal monólogo abrangerá diversos aspectos do filme, entre eles o tema, a mise en scène, os nomes dos entrevistados, locações, equipe, bem como as experiências sonoras e outras ações previstas pela produção. Na mesma banda sonora, concorrendo com o retesar da voz de Lemaître, notamos uma linha de vozes femininas em constantes experiências vocais. Entre o êxtase e a retidão rítmica, seu balé vocal fechará o filme com uma elucubração orgástica. Em L'amour, qu'est-ce?, novamente o projeto geral de negação de padrões comportamentais, do pornô e do melodrama culmina com a negação das imagens de origem. A sugestão predominante, em termos líricos, é a de um olhar pornô 
enquadrado por um discurso racionalizante, mas que é realimentado por um novo prazer, envolvendo especialmente dimensões rítmicas, táteis e sonoras - o que inclui a sensualidade dos corpos borrados, bem como os delírios da linha de vozes femininas.

O último dos curtas de Films d'amour é Chantal D. Star (1968). Em sua sessão, um apresentador falaria à plateia das intenções iniciais, ou seja, uma entrevista com uma starlet de cinema, cuja face se assemelhava àquela do quadro La toilette d'Esther, de Theodore Chassériau (LEMAÎTRE, 2007, p. 49). Hipoteticamente, como indicado pela voz over, tal entrevista seria filmada no modo cinéma vérité, sem o conhecimento da própria atriz. Por razões práticas e éticas, a obra final tomou outro curso: “[...] realizar um filme com uma mono-imagem, infinitamente torturada, como teria sido a referida atriz, e cujo som seria a própria entrevista. [...]" (LEMAÎTRE, 2007, p. 49, tradução nossa). Ao assistir Chantal D. Star, percebe-se um dispositivo definido: a suposta entrevista entre atriz e produtor, com um debate descontraído, porém de fundo técnico, sobre como seria o trabalho em um filme. Paralelamente, há criações visuais em cima de um torso feminino nu, extraído de La toilette d'Esther. A imagem da sensual Esther, que, na tela, prepara-se para seduzir o rei da Pérsia em uma passagem bíblica, é retomada a partir de múltiplas intervenções que propiciam uma dupla ironia: em relação ao ato de sedução de Esther, mas também à entrevista em curso na banda sonora, que envolve a sedução entre produtor e atriz, a partir de um debate que inclui o desejo pela nudez e sua negação. Em Chantal D. Star, os cinzelamentos têm o objetivo geral de ironizar as duas estrelas - a personagem do quadro e a atriz entrevistada em voz over. Entre as formas de intervenção, pode-se indicar: (1) cartelas com perguntas irônicas, incluindo suposições sobre as roupas íntimas da atriz, ou sobre o tamanho de seus seios; (2) passagens com fundo totalmente negro; (3) interferências coloridas, com palavras e desenhos sobre a imagem de Esther, ou então, ações mais drásticas aproximando-se de tachismos; (4) texturas devido ao banho da película em ácidos; (5) apresentação do busto feminino em negativo.

A interação, entre as ironias visuais e a seriedade descontraída da entrevista em over, relaciona-se com a ironia à sedução da estrela cinematográfica em geral. Isso inclui o deboche sobre sua inocência, entre outros atributos que a tornariam desejada pelos espectadores, ou então o deboche sobre as atrações por ela exercidas. A negação dos materiais de origem, nesse caso, dá-se a partir de uma nova sensualidade, somada à ironia e ao deboche. 
Extrapolando o debate dos filmes um a um, podem ser identificadas tensões composicionais que os aproximam do cinema letrista em geral. Em Films d'amour, tais continuidades colocam-se como intenções de fundo, que, por vezes, misturam-se. Entre elas, podemos destacar duas, que serão debatidas a seguir: as poesias dispostas sobre experimentações visuais; e a criação de paralelismos rítmicos.

\subsection{Poesias dispostas sobre experimentações visuais}

No cinema letrista, a preponderância do registro sonoro leva à inclusão de atuações poéticas, registradas na íntegra, associadas nos filmes ao jogo de imagens cinzeladas. Nesses momentos, enquanto ato, o cinema parece mimetizar as intervenções letristas, com grupos de poetas recitando suas lettries. Embora os efeitos audiovisuais sejam visionários, o destaque sonoro remete-nos a um tipo de trabalho bastante preciso e quase matemático. Vale lembrar que a experimentação letrista, no campo da poesia, envolve intenções mensuradas, com a criação de sistemas ou novos alfabetos e formas de notação para sonoridades corporais.

Dentro de Films d'amour, o fenômeno está presente especialmente nos curtas L'amour réinventé e L'amour, qu'est-ce?', nos quais as poesias são sobrepostas a experimentações visuais. Sob essa perspectiva, a união da experiência visual com os registros sonoros de poesias aproxima-se da noção letrista de "hipergrafia"10. 0 termo era usado para as artes plásticas, em telas que eram concebidas como uma união de fotografia, colagem, pintura e a presença de palavras escritas. Nos filmes, pode-se falar de uma hipergrafia que une a superfície visual, mas também as informações trazidas pelos elementos sonoros, potencialmente tomados como uma dimensão adicional aos elementos da hipergrafia visual. Assim sendo, quanto à sexualidade construída em Films d'amour, e particularmente em L'amour réinventé e L'amour, qu'est-ce?, pode-se falar da criação de uma sensibilidade hipergráfica audiovisual, uma ação que toma a superfície da tela como espaço de sobreposições e interações de gestos artísticos de diferentes naturezas, unindo sonoridade poética e visualidades cinzeladas. Nela, a sexualidade é reconstruída através de uma nova

\footnotetext{
${ }_{9}^{9}$ Poesias de Lemaître, presentes em L'amour réinventé: La ballade des mordus, de 1959; Nikazizu (balade), de 1963; Hymne a Xochipilli,de 1961; Vallanelle a l'oiseau, de 1963; Salut a Velemir Khlebnikov, de 1963. Para L'amour, qu'est-ce?: poesia não identificada, recitada por voz feminina.

10 Lemaître pensará na "hipergrafia" como uma união dos diferentes ramos da arte (romance, pintura, escultura, fotografia e escrita) em um novo meio de transcrição, estudado pela "hipergrafologia" (LEMAÎTRE, 1954, p. 93-102).
} 
sensualidade dos movimentos e massas audiovisuais, que pode ser aproximada de um lirismo multiartístico e coletivo.

\subsection{Criação de paralelismos rítmicos}

No cinema letrista, o cinzelamento tomado como cisão entre sons e imagens levará a uma criativa gama de assincronias. Entre as figuras existentes, encontraremos momentos nos quais imagens e sons se tornam matérias paralelas ou concorrentes, ou então, passagens nas quais esses dois elementos se unem verticalmente, passando por acelerações e desacelerações rítmicas. Trata-se de paralelismos ou contraposições que, porém, não contém precisões sistemáticas. Tal tendência, identificada em termos audiovisuais, apresenta-se também em anotações de roteiros letristas; é o caso do já comentado Le film est déjà commencé?, no qual há uma intenção de, a partir da montagem, criar ritmos visuais que dialoguem com os ritmos vocais. No conjunto Films d'amour, a possibilidade de tomar sons e imagens como elementos complementares ou concorrentes nos leva a duas tendências principais.

Primeiro caso: o registro de poesias de duração pontual em seus contatos com as composições imagéticas, que se dão a partir de rimas. 0 conjunto de atmosferas visuais de L'amour réinventé, por exemplo, será ritmicamente acompanhado por poesias como Hymne a Xochipilli, de 1961, e Nikazizu (balade), de 1963, cuja interação sugere a figura vertical de uma sinfonia ao mesmo tempo militar e sexual. Em L'amour, qu'est-ce?, os paralelismos com conotações sexuais têm continuidade; é o caso da linha sonora feminina, que acompanha momentaneamente as imagens em um recitar que se desdobra entre gemidos e exercícios parametrizados. Ao sobrepor-se a um close da atriz, a rima sugere um sentido vertical geral, que será retomado nas demais aparições da voz: a face como espaço de desejo, entre afirmações, negações e ironias.

Segundo caso: existência de longos registros sonoros, discursos ou conversas, que complementam as imagens em termos de contraste rítmico e de significados. Tal tendência explicita-se em filmes como Des scènes d'amour..., integralmente acompanhado por um discurso acadêmico, ou Chantal D. Star, pontuado pela longa entrevista, de função técnica, entre uma atriz e um produtor. Em ambos os casos, a tendência é recolocar o contraste entre duas formas de composição rítmica - fragmentação visual versus retesar sonoro -, a partir de uma experiência que acompanha a duração completa dos filmes. 


\section{Considerações finais}

Pelo trajeto realizado, percebe-se que, em Films d'amour, as interfaces entre cinzelamento e sexualidade sugerem um contato com o lirismo e a explosão do olhar presente nos materiais de origem, especialmente ante ao naturalismo do cinema clássico e à hiperfocalização do sexo no pornô. Como desdobramento, um bom campo teórico para o aprofundamento da sexualidade, em cotejo com o viés letrista, são algumas das teorias dos anos 1970, que questionam a construção do olhar e do prazer no cinema sob uma ótica de contraposição ao imaginário patriarcal, consolidado pelo cinema clássico e pelo pornô. Sob esse viés, Films d'amour poderia ser um dos antídotos ao erótico codificado dentro de uma ordem patriarcal dominante e próprio à decupagem clássica, examinado por Laura Mulvey (1983) em Prazer visual e cinema narrativo. 0 prazer visual implicado em tal cinema, no qual a imagem da mulher vista por um olhar masculino é central, implicaria em uma operação dupla e significativa. Por um lado, a escopofilia, ação instintiva que surge do "[...] prazer de usar uma outra pessoa como objeto de estímulo sexual através do olhar [...]" (MULVEY, 1983, p. 443); por outro lado, em uma ação do ego, haveria a "identificação" (MULVEY, 1983, p. 443) narcísica e fascinante do espectador com a sua autoimagem vista através do cinema. No cinema erótico letrista, a escopofilia enquanto ação de distanciamento é superada, tendendo-se a uma percepção lírica internalizada, na qual o próprio espectador é imbuído pelos estímulos audiovisuais fragmentares. 0 cinzelamento aniquila o distanciamento, bem como a possibilidade de um eu uno. A ação instintual é coletiva, envolvendo também o próprio espectador, que não mais verá, mas sim participará de uma percepção antiindividualizante. Quanto à identificação, apesar da vanguarda letrista ter predominância masculina entre os artistas, os filmes reverberarão tal presença, em um universo que tende a extrapolar as polaridades homem-mulher. 0 caráter coletivo, somado à dissolução de uma política dual de gêneros, impede a identificação e a construção de um olhar unificado. 0 prazer não está voltado a um corpo humano uno e identificável, mas sim a um deleite lírico dos impulsos audiovisuais. A dualidade escopofilia-identificação, presente na construção do prazer próprio ao cinema clássico, de acordo com Mulvey (1983), será substituída no letrismo por uma outra, já destacada ao longo das análises: aquela existente entre "liberdade versus teorização", que, como debatido, apresenta-se nos escritos eróticos e na construção estética dos filmes. Sob o viés das propostas de Mary Ann Doane (1983), o 
cinema erótico de Lemaître pratica uma espécie de extorsão, apropriando-se violentamente de imagens originalmente construídas sob viés de um imaginário patriarcal, que inscrevia o corpo feminino como subordinado, e no qual o prazer se associava ao fetiche masculino e a uma inventada neutralidade do dispositivo cinematográfico. (DOANE, 1981, p. 22) Ante a tais imagens, os filmes de Lemaître realizam uma voraz desnaturalização, com a desconstrução das imagens dadas, propondo uma nova sintaxe a tais corpos que se tornam fragmentos líricos.

Em contraste com o pornô, aquecido na passagem entre os anos 1960 e 1970, os materiais de Lemaître subvertem a sexualidade do plano de detalhe voltado ao prazer masculino. Em artigo publicado nos Cahiers du cinéma, Lardeau (1978) fará referência à fragmentação dos corpos via planos de detalhe, algo marcante no pornô. Segundo Lardeau (1978), trata-se de uma aproximação microscópica, baseada em um registro total e totalitário, visando à saturação e à divisão do espaço de forma sistemática (LARDEAU, 1978). Tal aproximação, porém, em sua desumanização e objetificação, levaria a uma exclusão de facto, que barraria o imaginário a partir de um prazer milimetricamente programado. Ao apropriar-se de materiais pornôs, os filmes de Lemaître aqui tratados lhes dão novo tratamento, superando a exclusão de facto pela inclusão lírica em um universo por vezes ainda mais fragmentar. 0 campo, recortado via plano de detalhe, passa a ser local de intervenções manuais enérgicas, sobreposições delirantes ou ironias. 0 desejo, antes voltado a um corpo diegeticamente identificável, é transformado, voltando-se à superfície da tela e às diferentes ordens de cinzelamento.

A possibilidade de um lirismo audiovisual letrista, por sua vez, é de interesse não apenas para a pesquisa da sexualidade em tal cinema, mas também para sua contextualização junto aos cinemas de vanguarda dos anos 1940-60, contexto esse no qual o achatamento da perspectiva e o pintar como forma de ação (ARGAN, 1992) afirmam-se no campo da arte moderna com interessantes reflexos no cinema. Será o caso do lirismo letrista, no qual o cinzelamento, tomado em suas diferentes dimensões, incluindo a atenção à superfície da tela, mimetiza uma existência coletiva e uma ação enérgica sobre o mundo.

\section{Referências}

ALBERA, François. La vanguardia en el cine. Buenos Aires: Manantial, 2009. 
ARGAN, Giulio Carlo. Arte moderna. São Paulo: Companhia das Letras, 1992.

AUMONT, Jaques; MARIE, Michel. Dicionário teórico e crítico de cinema. Campinas: Papirus, 2003.

AUMONT, Jaques; MARIE, Michel. L'analyse des films. Paris: Nathan, 2002.

BRAKHAGE, Stan. Metáforas da visão. In: XAVIER, Ismail (org.). A experiência do cinema. Rio de Janeiro: Graal, 1983. p. 341-352.

CABAÑAS, Kaira . Off-screen cinema: Isidore Isou and the lettrist avant-guarde. Chicago: University of Chicago Press, 2014.

CHANTAL D., Star. Direção: Maurice Lemaître. França, 1968. Suporte: 16mm (26 min), som ótico, cor.

CHION, Michel. La audiovision. Barcelona: Paidós, 1993.

DEBORD, Guy. Potlatch (1954-1957). Paris: Gallimard, 1996.

DES SCENES d'amour très réalistes avec force détails et gros plans. Direção: Maurice Lemaître. França, 1978. Suporte: Super-8 (18 min), cor, sonoro.

DOANE, Mary Ann. Woman's stake: filming the female body. October, Cambridge, v. 17, p. 22-36, 1981.

DOANE, Mary Ann. A voz no cinema: a articulação de corpo e espaço. In: XAVIER, Ismail (org.). A experiência do cinema. Rio de Janeiro: Graal, 1983. p. 457-475.

FILMS d'amour. Direção: Maurice Lemaitre. 1968-89. Versão em vídeo (78 min), som, cor, p \& b. Compila 5 curtas-metragens.

HURLEMENTS en faveur de Sade. Direção: Guy Debord. França, 1952. Suporte: 35mm (64 $\min ), \mathrm{p} \& \mathrm{~b}$.

ISOU, Isidore. Introduction à une nouvelle poésie et à une nouvelle musique. [Paris]: Gallimard, [1947].

ISOU, Isidore. Isou ou la mécanique des femmes. Paris: Aux escaliers de Lausanne, 1949.

ISOU, Isidore. Je vous apprendrai l'amour suivi de Traité d'érotologie mathématique et infinitésimale. Paris: Le terrain Vague, 1959.

L'AMOUR-SYSTÈME. Direção: Maurice Lemaître. França, 1979. Suporte: 16mm (17min), p\&b, som ótico.

L'AMOUR réinventé. Direção: Maurice Lemaître. França, 1979. Suporte: 16mm (15 min), cor, som ótico. 
L'AMOUR, qu'est-ce? Direção: Maurice Lemaître. Fança, 1976-1989. Suporte: 16mm (24 $\min )$, cor, sonoro.

L'ANTICONCEPT. Direção: Gil Wolman. França, 1952. Suporte: 35mm (61 min), p \& b, sonoro.

LARDEAU, Yann. Le sexe froid: du pornô et au dela. Cahiers Du Cinema, Paris, n . 289, p. 4963, 1978.

LE FILM est déjà commencé? Direção: Maurice Lemaître. França, 1951. Suporte: 35mm (62 $\min )$, sonoro, cor/p \& b.

LEMAÎTRE, Maurice. Oeuvres de cinema (1951-2007). Paris: Paris Experimental, 2007.

LEMAÎTRE, Maurice. Le café cinema Lemaître: huit films lettristes. Paris: Paris Experimental, 2003.

LEMAÎTRE, Maurice. Qu'est-ce que le Lettrisme? Paris: Fischbacher, 1954.

LEMAÎTRE, Maurice. Le film est déja commencé? Paris: Cahiers de l'externité, 1999.

LEMAÎTRE, Maurice. Le journal d'un dragueur ou L'amour-système. [Paris]: Le Terrain Vague, 1960.

MULVEY, Laura. Prazer visual e cinema narrativo. In: XAVIER, Ismail (org.). A experiência do cinema. Rio de Janeiro: Graal, 1983. p. 437-453.

SABATIER, Roland. Le lettrisme: les creations et lês createurs. Nice: Zéditions, 2000.

SABATIER, Roland. Le lettrisme/Les Théories du Lettrisme - l'erotologie. [20--].

SITNEY, Adams. The lyrical film. In: SITNEY, Adams. Visionary film. New York: Oxford University Press, 2002. p. 155-187.

TRAITÉ de bave et d'éternité. Direção: Isidore Isou. 1951. Suporte: 35mm (120 min), p \& b, sonoro.

\title{
Chiseling and Sexuality in Films d'amour (1968-89), by Maurice Lemaître
}

\begin{abstract}
Based on the set of short films Films d'amour, made by Maurice Lemaître, we try to question their main narrative traces, focusing on the questions about chiseling and sexuality in them. To do so, we start from the theoretical debate about filmic, extra filmic and lyric dimensions of chiseling, such as the
\end{abstract}


sexuality, in the context of the lettrist vanguard. In a second moment, the films are approached by a commented description, focused on the announced key issues, as well on the lettrist counterpoint to hegemonic patterns of sexuality, commons to classic and porn cinema. Finally, it is identified the existence of a particular sexuality, associated with lyricism, as well as the tensions between visual freedom and the rationalization of sound/ written elements. Among the developments, in relation to the theories about the construction of sexuality in cinema, we argue that Films d'amour will have a propitious conceptual field from authors like Laura Mulvey, Mary Ann Doane and Yann Lardeau, that, in the 1970s, distrusted visual pleasure and sexuality heirs to classic naturalism and the fragmentation of porn.

\section{Keywords}

Avant-guarde Cinema. Lettrism. Chiseling. Sexuality. Maurice Lemaître.

Recebido em 24/01/2018

Aceito em 16/07/2018 